\title{
Correspondence
}

\section{Patient admission and caregiver stress}

Although the distress of a patient is the primary concern of all clinicians, I feel that it is also important to understand the psychological experiences of carers, as they have significant responsibility in supporting someone who is mentally ill. I am therefore extremely satisfied to see the recent study by Ranieri et $a l^{1}$ which has investigated the link between patient admission and caregiver stress.

Overall, the article presents a strong finding which could assist in identifying the types of support needed by carers to ensure that their own mental health is protected.

However, one limitation of the study that was not identified by the authors is the use of self-report measures. Although the questionnaire instruments used have been found to be reliable measures, participants are not always honest in their responses due to possible embarrassment, or the social desirability bias. ${ }^{2}$ This means that a true reflection of an individual's psychological state is not always captured accurately.

Furthermore, I feel that 'suicidality' should have been included as an additional variable due to the close link with psychological distress. ${ }^{3}$ If a significant relationship was found, it might inform thinking around the types of support provided to carers.

Emily R Kruger, Assistant Psychologist, North Lincolnshire NHS Child and Adolescent Mental Health Service, Scunthorpe, UK, email: emilykrugerxo@hotmail.com

1 Ranieri V, Madigan K, Roche E, McGuinness D, Bainbridge E, Feeney L, et al. Caregiver burden and distress following the patient's discharge from psychiatric hospital. BJPsych Bull 2017; 41: 87-91.

2 Furnham A. Response bias, social desirability and dissimulation. Pers Individ Dif 1986; 7: 385-400.

3 Sokero TP, Melartin TK, Rytsala HJ, Leskela US, Lestela-Mielonen PS, Isometsa ET. Prospective study of risk factors for attempted suicide among patients with DSM-IV major depressive disorder. Br J Psychiatry 2005; 186: 314-8.

doi: $10.1192 / p b .41 .4 .237$

\section{Being sensible about suicides}

I must thank Nielssen et al for their thoughtful and concise piece on the high numbers of false positives produced by assessments of suicide risk and their conclusions that all patients, even those deemed to be at low risk of suicide, need to receive interventions. ${ }^{1}$ Having just been to an inquest into the death of a patient where the risk of suicide was deemed to be low, I can readily identify with the sentiments expressed in the paper, namely that our assessments of suicide risk are inadequate and that we should focus on care for all.

I am reminded of the Dangerous and Severe Personality Disorder (DSPD) Programme in this regard. This was a UK government initiative in response to a high-profile case of homicide by a patient with an antisocial personality disorder, where patients who fulfilled certain criteria (at risk of an offence causing serious physical or psychological harm, presence of a severe personality disorder, offending and disorder linked) were admitted to a treatment programme designed to reduce their risk to others. ${ }^{2}$ Unsurprisingly, there were concerns at the time that large numbers of patients who would never offend or present a significant risk to others would be incarcerated and prevented from living in the community. ${ }^{3}$ For those who are not aware, the initiative has now ended, following strong opposition from doctors and others. ${ }^{4}$

I have long been concerned about the premise that most suicides can be predicted and now I have some figures and knowledge to quote. Perhaps, like the DSDP Programme, we as a society need to recognise that prediction in retrospect is futile and follow the paper's recommendation of the provision of 'adequate care for all our patients'.

John Watts, Consultant Psychiatrist, South London and Maudsley NHS Foundation Trust, Kent and Medway Adolescent Unit, Staplehurst, UK, email: john.watts@nhs.net

1 Nielssen O, Wallace D, Large M. Pokorny's complaint: the insoluble problem of the overwhelming number of false positives generated by suicide risk assessment. BJPsych Bull 2017; 41: 18-20.

2 Probation circular. Dangerous and severe personality disorder (DSPD) programme. http://webarchive.nationalarchives.gov.uk/ 20060715141954/http://dspdprog . . . accessed 31 March 2017.

3 Duggan C. Dangerous and severe personality disorder. $\mathrm{Br} J$ Psychiatry 2011; 198 431-3.

4 Batty D. Q\&A: dangerous and severe personality disorder. The Guardian; 2002, 17 April.

doi: $10.1192 / p b .41 .4 .237 a$

\section{To educate or to entertain?}

Droning techno music, muted colours, hazy lenses, panning camera angles and extreme close-ups. These are features I expect in films such as The Shining or Silence of the Lambs, not a television documentary about schizophrenia. Why did I go mad? (BBC2 Horizon 2 May 2017) follows four individuals with a diagnosis and I cannot help but feel the BBC missed the point. Surely, the responsibility of the media today is to accurately represent mental illness, deepen understanding and reduce stigma. It was as if the four people were protagonists in their own horror movies. I was left questioning which I feared more, the psychosis or the person, and neither are helpful responses when it comes to changing our perceptions of the illness. I am disappointed in the BBC.

It is important to understand where stigma arises in order to challenge beliefs and attitudes, but what hope is there when documentaries care more about entertaining than educating?

Kiana H Newman-Zand, Second Year Medical Student, Queen's University Belfast, Belfast, UK, email: knewmanzand01@qub.ac.uk

doi: 10.1192/pb.41.4.237b

\section{Bulletin}

